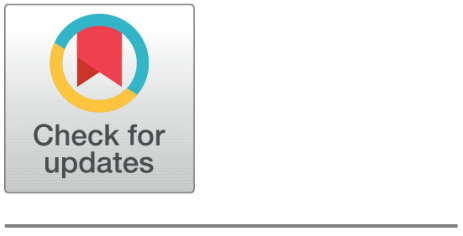

OPEN ACCESS

Received: 02.06.2020

Accepted: 14.10 .2020

Published: 22.10 .2020

Editor: Dr. Natarajan Gajendran

Citation: Acodile-Viado LAT, Namoco RA (2020) Efficiency analysis of select state universities and colleges in Southern Philippines using data envelopment analysis. Indian Journal of Science and Technology 13(38): 3970-3982. https ://doi.org/10.17485/IJST/v13i38.809

* Corresponding author.

rhodaagdeppanamoco@gmail.com

Funding: None

Competing Interests: None

Copyright: (c) 2020 Acodile-Viado \& Namoco. This is an open access article distributed under the terms of the Creative Commons Attribution License, which permits unrestricted use, distribution, and reproduction in any medium, provided the original author and source are credited.

Published By Indian Society for Education and Environment (iSee)

ISSN

Print: 0974-6846

Electronic: 0974-5645

\section{Efficiency analysis of select state universities and colleges in Southern Philippines using data envelopment analysis}

\author{
Lou Ann T Acodile-Viado ${ }^{1,2}$, Rhoda A Namoco ${ }^{1 *}$ \\ 1 Department of Applied Mathematics, College of Science and Mathematics, University of \\ Science and Technology of Southern Philippines, Lapasan, Cagayan de Oro, 9000, Philippines \\ 2 Mathematics Department, Bukidnon National High School, Malaybalay City, 8700, \\ Philippines
}

\section{Abstract}

Objectives: This study aims to evaluate the relative efficiency of select state universities and colleges (SUCS) in Southern Philippines using the inputoriented constant returns to scale (CRS) model and input-oriented variables returns to scale (VRS) model of data envelopment analysis (DEA). Methods: The input-oriented CRS and VRS model of the DEA is applied to analyze efficiency of selected state universities and colleges in Southern Philippines using four inputs (namely, Number of faculty members, personnel services and maintenance and other operating expenses (PS+MOOE), estimated cost per student, and tuition fee) and three outputs (namely, number of students enrolled, PRC rating, and number of graduates) as parameters. DEA works by comparing each decision-making unit (DMU) and classifies them as either efficient or less efficient. It also provides information on how these less efficient DMUs can be improved. Findings: Results of the study show how each unit perform when compared to other units. It showed that among the 26 SUCS considered in this study, only ten (10) SUCS are identified efficient and the remaining sixteen (16) SUCS are less efficient under the input-oriented CRS model. On the other hand, only thirteen (13) SUCs are identified efficient while the remaining thirteen (13) are less efficient under the input-oriented VRS model. These difference in the results from the two DEA models used may be due to the fact that CRS tends to lower the efficiency score while the VRS tends to raise the efficiency score. Application: DEA provides insights on how the less efficient SUCs can be improved by adopting the efficiency reference set (ERS) weights of the identified efficient SUCS against the less efficient SUCs in order to improve efficiency. In this way, results of this study provide insights on how the less efficient SUCs in Southern Mindanao can be helped for them to become efficient units.

Keywords: Efficiency; higher education; data envelopment analysis 


\section{Introduction}

Each country values education because it is the way for upward social and economic mobility. It is also responsible in offering capable and competent human resources who will have the ability to perform day-to-day tasks according to the standards that are set by the society. It additionally breaks the bounds made by the differences in a diverse society and encourages the citizens to come together for progress to be done. Just like any educational institutions elsewhere in the world, the fundamental aspiration of the Philippine education is to enhance the quality of life of every Filipino.

Education in the Philippines is managed and regulated by the Department of Education (DepEd), Commission on Higher Education (CHED) and Technical Education and Skills Development Authority (TESDA). DepEd is responsible for the K-12 basic education; it exercises full and exclusive control over public schools and nominal regulation over private schools, and it also enforces the national curriculum that has been put in place since 2013. CHED and TESDA, on the other hand, are responsible for higher education; CHED regulates the academically-oriented universities and colleges while TESDA oversees the development of technical and vocational education institutions and programs in the country.

The assessment of performance of state universities and colleges (SUCs) in the Philippines is important in view of the long-standing issues and concerns that beset the country's system of higher education. In particular, the higher education subsector is haunted by issues of (i) limited and inequitable access to higher education; (ii) inequitable financing of public higher education; (iii) lack of overall vision, framework, and plan for higher education resulting in the proliferation of low quality higher education institutions (HEIs) and programs, oversubscribed and undersubscribed programs as well as skills and job mismatch; (iv) deteriorating quality of higher education due to inadequate faculty credentials and as indicated by the declining performance of graduates in professional licensure exams; (v) crowding out of private provision; and (vi) underdeveloped innovation system ${ }^{(1)}$.

Determining the efficiency of educational institution is of great importance. Efficiency analysis of HEIs will allow decisionmaking units to define policies and guidelines that will improve quality, redirecting policies and decision-making to improve efficiency according to research findings. It translates into actions based on proven empirical evidence, and not on the beliefs and perceptions of the faculty of the institutions or policy guidelines ${ }^{(2)}$.

Several techniques have been developed, and have been applied to estimate the efficiency of educational organizations. These include econometric approaches that utilize ordinary least squares regression and stochastic frontier estimation as well as a group of linear programming approaches falling under the rubric of Data Envelopment Analysis (DEA) ${ }^{(2-4)}$.

Efficiency means that a school achieves maximum results possible with the limited resources it has. This corresponds to the definition of a production function which shows maximum possible output at a given level of input. In this sense schools may be viewed as production units that use inputs and produce outputs. And, even though, one cannot say what the maximum level of output possible is, one can estimate it by observing the schools that produce most outputs at the given level of input. Inefficiency is then measured using the distance between a given school and the most efficient schools. This is the basic principle of the Data Envelopment Analysis.

Data Envelopment Analysis is known as the method of evaluating the performances of relative decision-making units (DMUs). It provides a single measure and easily deals with multiple inputs and multiple outputs. In DEA, comparative efficiency indicators of the units to evaluate are provided. These units were called the Decision-making units (DMU's). The efficiency of a DMU is measured relative to all other DMUs with the simple restriction that all DMUs lay on or below the extreme frontier. The efficiency frontier is a set of segments interconnecting all the efficient DMUs and it acts as an envelope for inefficient units. An inefficient unit can be enveloped below called input-oriented model or above which is the output-oriented model. DEA has become an extensively studied, application driven 'multipurpose tool' for analysing Decision Making Units (DMUs) that consume multiple inputs to produce multiple outputs where the meaning of the words "DMU", "input", and "output" can be quite freely interpreted. In brief, the DEA is a useful method since it truly estimates efficiency by comparing a unit to the best performing units not to average as regression does; and it can model multi-input and output nature of educational production $^{(5,6)}$.

Evaluation of school performance is the main issue in the educational system. A current approach to school evaluation considers the school as production unit that uses multiple inputs (resources) and produces multiple outputs (outcomes). In such a setting, the definition and measurement of the inputs and outputs that reflects the operation of a school for evaluation is not an easy task ${ }^{(7)}$.

Studies on the efficiency of state universities and colleges (SUCs) in the Philippines have been made, and some of these used DEA in their evaluation. The paper by Cuenca ${ }^{(7)}$ looked into the efficiency of SUCs in the whole Philippines using DEA by considering expenditure data as input parameter and number of enrolled students, number of graduates and total revenue for 78 SUCs in the country. The study identified that majority of the SUCs included in the study were less efficient based on the parameters considered. Another paper ${ }^{(5)}$ looked into the efficiency of 59 SUCs all over the Philippines and found out that 49 
SUCs were efficient. This study considered as its input parameters the (1) number of faculty members, (2) property, plant and equipment, and (3) operating expenses, while the (1) number of students enrolled, (2) graduates and (3) total revenue. While these studies looked into a broader scope, it must be emphasized that limiting the scope for DEA studies has its own advantages. Due to the need for homogeneity among DMUs considered in a DEA study, it is believed that by focusing only on a particular locality would bring better assessment of the SUCs belonging to a similar locality.

This study explores the use of DEA methodology to assess the efficiency of the SUCs in Southern Philippines by considering the input-oriented CRS model and input-oriented VRS model. Specifically, this study aims to identify which institutions are efficient and what aspects are needed to be adjusted in less efficient SUCs using data from the period 2012-2016. Efficiency scores of each SUC are generated by DEA which determines whether it is efficient or less efficient. This study focuses only on assessing the efficiency of educational institutions, specifically SUCs in Southern Philippines, a total of twenty-six (26) DMUs. The parameters considered in this study are based on local and foreign papers by various authors ${ }^{(1,2,7-9)}$. Hence, the number of faculty members, PS+MOOE, estimated cost per student, and tuition fee are considered as the input parameters while the number of students enrolled, PRC rating, and number of graduates were considered as output parameters in this study.

This paper is organized as follows. Section 1 gives a brief introduction of the problem considered in this paper. Parameters used in this study are presented in Section 2. Section 3 describes the methodology used while section 4 presents the results obtained in this study. A brief conclusion is given in section 5 .

\section{Parameter setting}

DEA is a linear programming-based methodology that has proven to be a successful tool in measuring efficiency. In this study, the Decision-Making Units (DMUs) are the State Universities and Colleges in Southern Philippines (SUCs), which are shown in Table 1 (presented in alphabetical order). It should be noted that in the presentation of results later in this paper, identities of these DMUs are concealed, and therefore do not necessarily follow this order, for purposes of confidentiality.

Table 1. List of SUCs considered as DMUs in this study.

\begin{tabular}{|c|c|c|}
\hline Adiong Memorial Polytechnic State College & $\begin{array}{l}\text { Agusan del Sur College of Agriculture and } \\
\text { Technology }\end{array}$ & Basilan State College \\
\hline Bukidnon State University & Caraga State University & Central Mindanao University \\
\hline Cotabato City State Polytechnic College & $\begin{array}{l}\text { Cotabato Foundation College of Science and } \\
\text { Technology }\end{array}$ & Davao del Norte State Colleges \\
\hline $\begin{array}{l}\text { Davao Oriental State Colleges of Science and } \\
\text { Technology }\end{array}$ & J.H. Cerilles State College & Jose Rizal Memorial State University \\
\hline $\begin{array}{l}\text { University of Science and Technology of } \\
\text { Southern Philippines }\end{array}$ & $\begin{array}{l}\text { Misamis Oriental State Colleges of Agricul- } \\
\text { ture and Technology }\end{array}$ & $\begin{array}{l}\text { Northwestern Mindanao State College } \\
\text { of Science and Technology }\end{array}$ \\
\hline $\begin{array}{l}\text { Southern Philippines Agribusiness, Marine } \\
\text { and Aquatic School of Technology }\end{array}$ & Sultan Kudarat State University & Surigao del Sur State University \\
\hline Surigao State College of Technology & Tawi-tawi Regional Agricultural College & University of Southeastern Philippines \\
\hline University of Southern Mindanao & Western Mindanao State University & $\begin{array}{l}\text { Zamboanga City State Polytechnic } \\
\text { College }\end{array}$ \\
\hline $\begin{array}{l}\text { amboanga State College of Marine Sciences } \\
\text { d Technology }\end{array}$ & & \\
\hline
\end{tabular}

The parameters used in this study are defined as follows.

Input parameters considered in this study are (1) the number of faculty members, (2) personnel services and maintenance and other operating expenses (PS+MOOE), (3) estimated cost per student, and (4) tuition fee.

- The faculty members refer to the number of full-time and part time faculty members of an institution.

- Personal Services (PS) refers to the provisions for the payment of salaries, wages and other compensation/benefits. They cover permanent, temporary, contractual and casual employees of the government. Maintenance and Other Operating Expenses (MOOE) refers to recurring expenses to cover day-to-day requirements of agencies to carry out their regular operations

- Estimated Cost per Student refer to the ratio of SUC's PS+MOOE and Weighted Enrolment. 
Output parameters are (1) students enrolled, (2) PRC rating, and (3) graduates.

- Enrollment refers to the number of students enrolled in a given year.

- Professional Regulation Commission (PRC) rating refers to the ratio of number of licensure exam passers to takers in each SUC.

- Graduates refer to the total graduates per year of each SUC.

Tables 2 and 3 show the average data for input and output parameters used in this study. These data are taken from the Commission on Higher Education (CHED) State Universities and Colleges Statistical Bulletin within the time period of 20122016. There are four inputs and three outputs that are considered in the study. The inputs are the number of faculty, the PS+MOOE (000'), the estimated cost per student and the tuition fee. On the other hand, enrolment, graduates and the PRC passing rates serve as the output.

Table 2. The average data for input parameters

\begin{tabular}{|c|c|c|c|c|}
\hline \multirow{2}{*}{ DMU } & \multicolumn{4}{|c|}{ INPUT } \\
\hline & FACULTY & PS+MOOE (Million & ESTIMATED COST PER STUDENT & TUITION FEE \\
\hline DMU 1 & 699 & 88439 & 8482.8 & 224 \\
\hline DMU2 & 419 & 213565.6 & 18604.8 & 205 \\
\hline DMU3 & 1057 & 355943.8 & 12785.6 & 200 \\
\hline DMU4 & 199 & 87213.6 & 15023.6 & 191.67 \\
\hline DMU5 & 144 & 103140.2 & 18107.2 & 175 \\
\hline DMU6 & 150 & 59927.8 & 11265.6 & 246.67 \\
\hline DMU7 & 110 & 54121.8 & 17151 & 137.5 \\
\hline DMU8 & 1250 & 137282 & 5701.8 & 375 \\
\hline DMU9 & 98 & 45903.6 & 15158.2 & 187 \\
\hline DMU10 & 376 & 345238.4 & 31978.8 & 471 \\
\hline DMU11 & 470 & 152258.8 & 14899.6 & 425 \\
\hline DMU12 & 64 & 48479.6 & 41390.2 & 333.33 \\
\hline DMU13 & 59 & 24455 & 11895 & 150 \\
\hline DMU14 & 83 & 62207.4 & 31704.2 & 242.67 \\
\hline DMU15 & 253 & 89920.8 & 10791.8 & 196.5 \\
\hline DMU16 & 144 & 60857 & 18467.2 & 283.33 \\
\hline DMU17 & 506 & 301436.6 & 18500.8 & 310 \\
\hline DMU18 & 149 & 87124.2 & 14479.2 & 190 \\
\hline DMU19 & 108 & 83791.8 & 26004.2 & 286.67 \\
\hline DMU20 & 349 & 128391.8 & 10947 & 283.33 \\
\hline DMU21 & 490 & 343742.2 & 22300.8 & 405 \\
\hline DMU22 & 20 & 23393.6 & 14290.2 & 125 \\
\hline DMU23 & 75 & 56937 & 18718 & 200 \\
\hline DMU24 & 274 & 112618.4 & 16149 & 306.67 \\
\hline DMU25 & 347 & 160193.6 & 15326.8 & 314.17 \\
\hline DMU26 & 299 & 145507.4 & 14768.8 & 350 \\
\hline
\end{tabular}


Table 3. The average data for output parameter

\begin{tabular}{|c|c|c|c|}
\hline \multirow{2}{*}{$\mathrm{DMU}$} & \multicolumn{3}{|c|}{ OUTPUT } \\
\hline & ENROLLMENT & PRC PASSING RATE & GRADUATES \\
\hline DMU1 & 10344 & 25.56 & 1803 \\
\hline DMU2 & 10249 & 33.46 & 1634 \\
\hline DMU3 & 25818 & 36.80 & 3201 \\
\hline DMU4 & 5647 & 18.56 & 881 \\
\hline DMU5 & 5516 & 29.10 & 746 \\
\hline DMU6 & 4232 & 15.90 & 1463 \\
\hline DMU7 & 3766 & 4.68 & 349 \\
\hline DMU8 & 23449 & 32.24 & 3524 \\
\hline DMU9 & 2932 & 38.34 & 719 \\
\hline DMU10 & 10371 & 60.21 & 1519 \\
\hline DMU11 & 11504 & 52.05 & 1606 \\
\hline DMU12 & 1059 & 42.39 & 203 \\
\hline DMU13 & 2131 & 41.70 & 383 \\
\hline DMU14 & 1393 & 59.68 & 589 \\
\hline DMU15 & 8521 & 53.98 & 1373 \\
\hline DMU16 & 3019 & 30.03 & 449 \\
\hline DMU17 & 15845 & 56.63 & 2395 \\
\hline DMU18 & 6904 & 14.79 & 970 \\
\hline DMU19 & 3198 & 16.90 & 573 \\
\hline DMU20 & 10913 & 32.62 & 1896 \\
\hline DMU21 & 15175 & 34.25 & 2655 \\
\hline DMU22 & 2280 & 9.65 & 399 \\
\hline DMU23 & 2965 & 26.64 & 343 \\
\hline DMU24 & 6655 & 42.85 & 811 \\
\hline DMU25 & 10055 & 30.69 & 1834 \\
\hline DMU26 & 9328 & 26.79 & 1263 \\
\hline
\end{tabular}

\section{Formulation of DEA model to assess the efficiency of SUCs}

In this study, DEA Input-Oriented Constant Returns to Scale (CRS) model and Input-Oriented Variables Returns to Scale (VRS) model are used to achieve the efficiency results of selected SUCs in the Philippines. Both models are used in the study to determine the efficiency of SUCs because it is uncertain that SUCs perform at optimal scale ${ }^{(1)}$.

In the case of a CRS model, it is assumed that an increase in the amount of inputs consumed would lead to a proportional increase in the amount of outputs produced. CRS reflects the fact that output will change by the same proportion as inputs are changed. In the VRS model, the amount of outputs produced is deemed to increase more or less than the increase in the inputs. VRS reflects the fact that outputs generated may exhibit increasing, constant and decreasing returns to scale. The two input-oriented DEA models are utilized to compare all of the resources used (input parameters) and services provided (output parameters) of each selected SUCs. CRS model tends to lower the efficiency score while VRS model tends to raise efficiency score.

Inputs should be carefully controlled to ensure the quality of state universities and colleges. This is because the quality of inputs determines the quality of outputs. The production process must be properly monitored in the state universities and colleges system in order to determine the quality of outputs.

Let

$\theta$ be the efficiency score for DMU k

$\mathrm{Y}_{k j}$ be the average value of output $\mathrm{k}$ for DMU $\mathrm{j}$

$\mathrm{X}_{i j}$ be the average value of input i for DMU $\mathrm{j}$

$\mathrm{V}_{i}$ be the weighted input assigned by DEA 
$\mathrm{U}_{k}$ be the weighted output assigned by DEA

$\lambda_{j}$ be the weights of the DMUs

$\mathrm{j}$ be the DMUs being compared by DEA

$i$ be the input parameters used by DMU $j$

$\mathrm{k}$ be the output parameters used by DMU $\mathrm{j}$

$\mathrm{n}$ be the number of DMUs being considered in $\mathrm{k}$

$\mathrm{p}$ be the number of outputs being considered in $\mathrm{k}$

$\mathrm{q}$ be the number of inputs being considered in $\mathrm{i}$

The equation below shows the Input-oriented CRS model.

$$
\operatorname{Min} \theta=\left[\frac{\left(\sum_{j=1}^{n} U_{j} Y_{k j}\right)}{\left(\sum_{j=1}^{n} V_{i} X_{i j}\right)}\right]
$$

subject to

$$
\begin{gathered}
{\left[\frac{\left(\sum_{i=1}^{n} U_{j} Y_{k j}\right)}{\left(\sum_{i=1}^{n} V_{i} X_{i j}\right)}\right] \leq 1} \\
\sum_{j=1}^{n} \lambda_{i} X_{i j} \leq \theta X_{i 0} \quad i=1,2, \ldots . q \\
\sum_{j=1}^{n} \lambda_{J} Y_{k j} \geq \theta \mathrm{Y}_{\mathrm{k} 0}, \quad \mathrm{k}=1,2, \ldots, \mathrm{p} \\
\lambda_{\mathrm{j}} \geq 0 \quad \mathrm{j}=1,2 \ldots ., \mathrm{n}
\end{gathered}
$$

For the VRS model, another constraint is added

$$
\sum_{j=1}^{n} \lambda_{j}=1 \quad \mathrm{j}=1,2, \ldots, \mathrm{n}
$$

The equivalent form of linear programming model of the above equation is shown below:

$$
\begin{aligned}
& \operatorname{Min} \theta \\
& \text { s.t. } \\
& \sum_{j=1}^{n} \lambda_{j} x_{i j}-\theta_{i o} \leq 0 \\
& \sum_{j=1}^{n} \lambda_{j} x_{k j}-\theta_{k o} \geq 0 \\
& \sum_{j=1}^{n} \lambda_{j}=1 \quad \text { Add (VRS) } \\
& \lambda_{j} \geq 0
\end{aligned}
$$

In other words, this study tries to minimize $\Theta$, the efficiency score in equation (1), subject to the constraints (a) that will provide an efficiency rating between zero and one which is generally practice. Constraint (b) corresponds to the sum product of inputs and weights of the services unit less than or equal to the inputs of the services unit being evaluated. Lastly, (c) is the sum product of outputs and weights of the service units greater than or equal to the service being assessed. Weights of each departments are given by DEA, and the other service units with non-zero lambda values are the units in the efficiency reference set (ERS). Relative weights are the weights assigned to inputs and outputs have systematic values. The other DMUs with non-zero lambda $(\lambda)$ values are the units in the Efficiency Reference Set (ERS).

Data envelopment analysis (DEA) is a powerful mathematical method that utilizes linear programming (LP) to determine the relative efficiencies of a set of functionally similar decision-making units ${ }^{8}$. In this study, each SUC are compared with regards on the inputs and outputs. It also determines the most efficient and the least efficient departments of the said institution. 
To solve for the relative efficiency of each DMU in DEA, formulation of DEA model in spread sheet is required and Excel Solver is used to calculate the efficiency of units. If the efficiency score of the unit is one $(\theta=1)$, that unit is classified to be $100 \%$ relatively efficient (best practices). On the other hand, if the efficiency score of the unit is less than one $(\theta<1)$, it implies that the relative efficiency score of that unit being evaluated is less than $100 \%$, hence, that unit is less efficient.

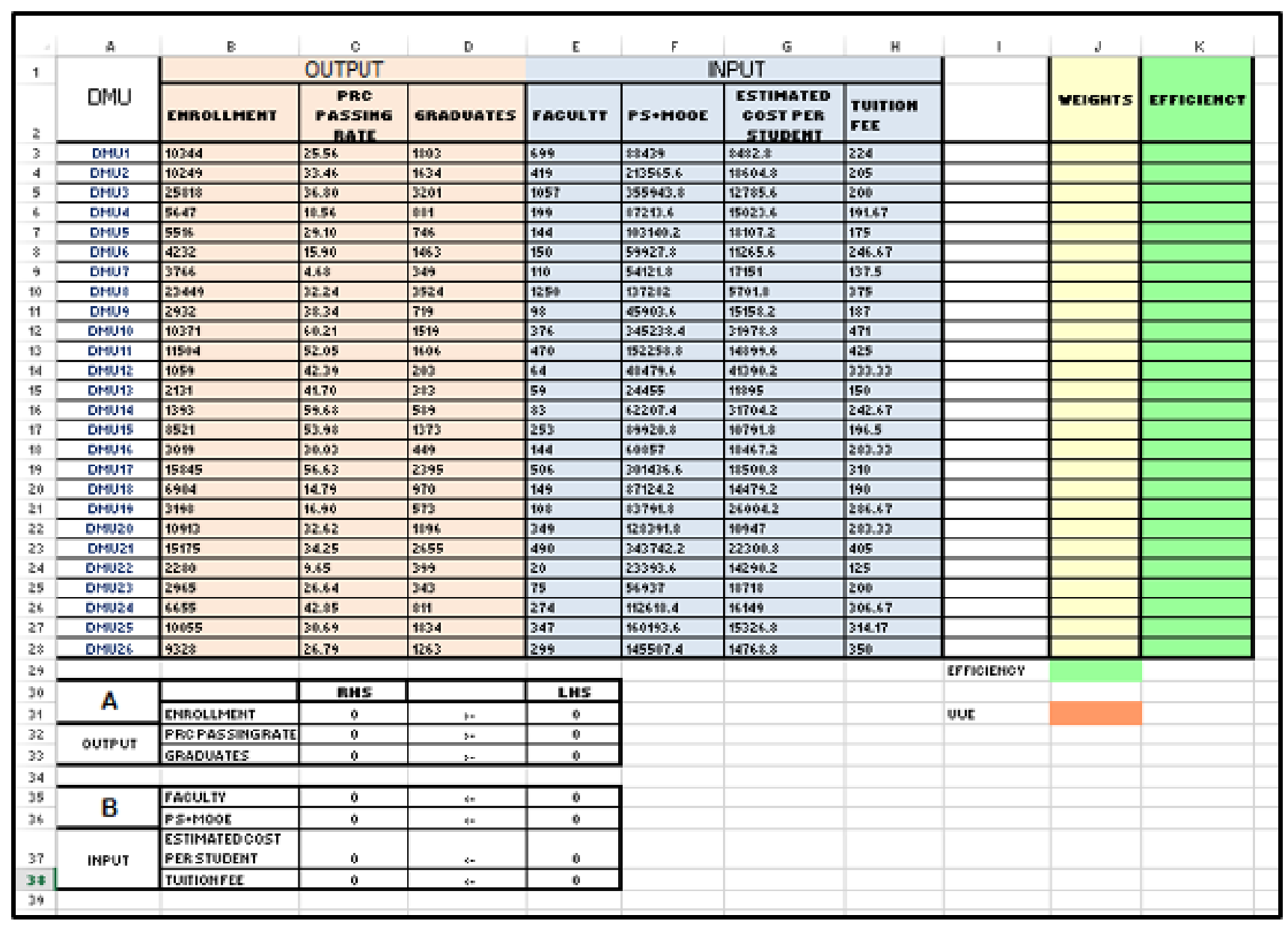

Fig 1. Excel solver setup for the CRS and VRS DEA models.

The set of units to be evaluated and the data (inputs and outputs) needed to apply in DEA have to be identified. The data are the actual inputs $i$ used and outputs $k$ generated. This means that the amount of $\mathrm{i}^{\text {th }}$ input used by the $\mathrm{j}^{\text {th }}$ unit and the amount of $\mathrm{k}^{\text {th }}$ output generated by the $\mathrm{j}^{\text {th }}$ unit are required in order to evaluate the relative efficiency of units.

All DMUs are being evaluated to identify if they are efficient or less efficient. The results of the efficiency rating lie within the interval of zero (0) and one (1). The best practices units are relatively efficient and are identified by an efficiency score of one $(\theta$ $=1$ ). This defines that the relatively efficient unit where there is no chance to improve efficiency compared with the performance of other unit in the data. The less efficient units are identified by an efficiency score of less than one $(\theta<1)$. Efficiency is achieving the goal with lesser resources. Therefore, in this study, efficient SUCs are those who have high output parameters but lesser input parameters (resources) while the less efficient SUCs are those who have high input measures but lesser outputs.

DEA is a very powerful technique in benchmarking ${ }^{(3,5)}$. There is a need to evaluate less efficient DMUs so that efficiency can be improved. Improvement can be acquired by making each less efficient unit as efficient as to the identified efficient "best practices" units. Specific changes can be classified for the less efficient units through solving the composite values. In order to compute the composite values, it requires the Efficiency Reference Set (ERS) weights. ERS, which is represented by $\lambda$, indicates the relatively efficient units against the less efficient units. This shows the set of ERS units that produce as much or more outputs and use less inputs, providing information as to how to improve efficiency of the less efficient units. 
Composite values are obtained from the sum of the assigned ERS weights of the efficient unit against the less efficient units and then multiplied to the actual outputs and inputs of the efficient units. It indicates the combination of the operating techniques utilized by the efficient units. The results computed can create a composite hypothetical branch that processes the same number or amount of outputs generated but requires lesser inputs used than the less efficient unit.

\section{Results and Discussions}

Efficiency ratings both for the CRS and VRS models are shown in Table 4. DMUs with an efficiency score of 1 or $100 \%$ is considered to be best practice set or efficient school while DMUs that has an efficiency score of less than 1 or $100 \%$ is considered to be less efficient.

Table 4. The Input-Oriented CRS and VRS efficiency ratings

\begin{tabular}{|c|c|c|c|c|c|}
\hline & \multirow{2}{*}{ DMU } & \multicolumn{4}{|c|}{ efficiency } \\
\hline & & CRS & In percent & VRS & In percent \\
\hline 1 & DMU1 & 0.90130826 & 90.13 & 1 & 100 \\
\hline 2 & DMU2 & 0.90019243 & 90.01 & 0.925536206 & 92.55 \\
\hline 3 & DMU3 & 1 & 100 & 1 & 100 \\
\hline 4 & DMU4 & 0.751573718 & 75.16 & 0.830240381 & 83.02 \\
\hline 5 & DMU5 & 0.937437102 & 93.74 & 0.938409262 & 93.84 \\
\hline 6 & DMU6 & 1 & 100 & 1 & 100 \\
\hline 7 & DMU7 & 0.797978346 & 79.80 & 0.943526522 & 94.35 \\
\hline 8 & DMU8 & 1 & 100 & 1 & 100 \\
\hline 9 & DMU9 & 0.976732861 & 97.67 & 0.980774197 & 98.08 \\
\hline 10 & DMU10 & 0.703248523 & 70.32 & 1 & 100 \\
\hline 11 & DMU11 & 0.810018533 & 81 & 0.876927105 & 87.69 \\
\hline 12 & DMU12 & 0.922099323 & 92.21 & 0.93626599 & 93.63 \\
\hline 13 & DMU13 & 1 & 100 & 1 & 100 \\
\hline 14 & DMU14 & 1 & 100 & 1 & 100 \\
\hline 15 & DMU15 & 1 & 100 & 1 & 100 \\
\hline 16 & DMU16 & 0.542094955 & 54.21 & 0.633053963 & 63.31 \\
\hline 17 & DMU17 & 1 & 100 & 1 & 100 \\
\hline 18 & DMU18 & 1 & 100 & 1 & 100 \\
\hline 19 & DMU19 & 0.530383375 & 53.04 & 0.535680704 & 53.57 \\
\hline 20 & DMU20 & 1 & 100 & 1 & 100 \\
\hline 21 & DMU21 & 0.949561582 & 94.96 & 1 & 100 \\
\hline 22 & DMU22 & 1 & 100 & 1 & 100 \\
\hline 23 & DMU23 & 0.761282964 & 76.13 & 0.811336366 & 81.13 \\
\hline 24 & DMU24 & 0.685650174 & 68.57 & 0.701995852 & 70.20 \\
\hline 25 & DMU25 & 0.887557858 & 88.76 & 0.913876734 & 91.39 \\
\hline 26 & DMU26 & 0.881607927 & 88.16 & 0.885217272 & 88.52 \\
\hline
\end{tabular}

It can be seen that in CRS model, out of the 26 SUCs there are 16 schools whose efficiency scores are less than $100 \%$ which is considered to be less efficient. The less efficient schools are the following: DMU1, DMU2, DMU4, DMU5, DMU7, DMU9, DMU10, DMU11, DMU12, DMU16, DMU19, DMU21, DMU23, DMU24, DMU25, and DMU26. In order for these less efficient SUCs to benefit from this study, they should minimize their inputs in accordance to the amounts calculated by the CRS DEA model to become efficient.

In VRS model, out of the 26 SUCs there are 13 schools whose efficiency scores are less than $100 \%$ which is considered to be less efficient. The less efficient schools are the following: DMU2, DMU4, DMU5, DMU7, DMU9, DMU11, DMU12, DMU16, DMU19, DMU23, DMU24, DMU25, and DMU26. In order for the inefficient or less efficient schools to benefit from this study, DMUs should minimize their inputs in accordance to the amounts calculated by the VRS DEA model to become efficient.

Based on the results, it can be observed that CRS model produces a fewer number of efficient units and has lower efficiency scores among all the DMUs compared to VRS model.

Figure 2 presents the efficiency reference set (ERS) or the benchmarks of less efficient schools assessed in CCR input-oriented model. These ERS includes the group of schools against which each inefficient school was found to be most directly inefficient. 


\begin{tabular}{|c|c|c|c|c|c|c|c|c|c|c|c|c|c|c|c|c|}
\hline \multicolumn{17}{|c|}{ EFFICIENCY REFERENCE SETS (ERS) } \\
\hline & DMU1 & DMU 2 & $\mathrm{DMU}_{4}$ & DMU5 & DMU7 & DMU 9 & DMU 10 & DMU 11 & DMU 12 & DMU 16 & DMU 19 & DMU 21 & DMU 23 & DMU 24 & DMU 25 & DMU 26 \\
\hline DMU 1 & 0 & 0 & 0 & 0 & 0 & 0 & 0 & 0 & 0 & 0 & 0 & 0 & 0 & 0 & 0 & 0 \\
\hline DMU2 & 0 & 0 & 0 & 0 & 0 & 0 & 0 & 0 & 0 & 0 & 0 & 0 & 0 & 0 & 0 & 0 \\
\hline DMU 3 & 0.006671794 & 0.22756062 & 0 & 0 & 0 & 0 & 0 & 0.023125804 & 0 & 0 & 0 & 0.025532285 & 0 & 0 & 0 & 0 \\
\hline DMU 4 & 0 & 0 & 0 & 0 & 0 & 0 & 0 & 0 & 0 & 0 & 0 & 0 & 0 & 0 & 0 & 0 \\
\hline DMU 5 & 0 & 0 & 0 & 0 & 0 & 0 & 0 & 0 & 0 & 0 & 0 & 0 & 0 & 0 & 0 & 0 \\
\hline DMU 6 & 0 & 0.252709984 & 0.023850924 & 0 & 0 & 0.235303011 & 0 & 0 & 0 & 0 & 0.039512078 & 0.299990048 & 0 & 0 & 0.230658398 & \\
\hline DMU 7 & 0 & 0 & 0 & 0 & 0 & 0 & 0 & 0 & 0 & 0 & 0 & 0 & 0 & 0 & 0 & 0 \\
\hline DMU 8 & 0.420775162 & 0 & 0 & 0 & 0 & 0 & 0 & 0.042557101 & 0 & 0 & 0 & 0 & 0 & 0 & 0 & 0 \\
\hline DMU 9 & 0 & 0 & 0 & 0 & 0 & 0 & 0 & 0 & 0 & 0 & 0 & 0 & 0 & 0 & 0 & 0 \\
\hline DMU 10 & 0 & 0 & 0 & 0 & 0 & 0 & 0 & 0 & 0 & 0 & 0 & 0 & 0 & 0 & 0 & 0 \\
\hline DMU 11 & 0 & 0 & 0 & 0 & 0 & 0 & 0 & 0 & 0 & 0 & 0 & 0 & 0 & 0 & 0 & 0 \\
\hline DMU 12 & 0 & 0 & 0 & 0 & 0 & 0 & 0 & 0 & 0 & 0 & 0 & 0 & 0 & 0 & 0 & 0 \\
\hline DMU 13 & 0 & 0 & 0 & 0 & 0 & 0.745628021 & 0.559170029 & 0 & 0.060093374 & 0.442933137 & 0.033347956 & 0 & 0.41026439 & 0.188110981 & 0 & 0 \\
\hline DMU 14 & 0 & 0 & 0 & 0 & 0 & 0 & 0 & 0 & 0.668299368 & 0 & 0 & 0 & 0 & 0 & 0 & 0 \\
\hline DMU 15 & 0.217648884 & 0.390286781 & 0.380480414 & 0.423079225 & 0.182423494 & 0.64949864 & 0.482229881 & 0.708803618 & 0 & 0.176165222 & 0.131411093 & \begin{tabular}{|l}
1.554541672 \\
\end{tabular} & 0.065048628 & 0.604823748 & 0.589669282 & 0.057629929 \\
\hline DMU 16 & 0 & 0 & 0 & 0 & 0 & 0 & 0 & 0 & 0 & 0 & 0 & 0 & 0 & 0 & 0 & 0 \\
\hline DMU 17 & 0 & 0 & 0 & 0 & 0 & 0 & 0 & 0 & 0 & 0 & 0 & 0 & 0 & 0 & 0 & 0 \\
\hline DMU 18 & 0 & 0 & 0.33371803 & 0.12651999 & 0.251301392 & 0 & 0.734404382 & 0 & 0 & 0.02674503 & 0 & 0 & 0.033421078 & 0.159390548 & 0.0760437 & 0.467836658 \\
\hline DMU 19 & 0 & 0 & 0 & 0 & 0 & 0 & 0 & 0 & 0 & 0 & 0 & 0 & 0 & 0 & 0 & 0 \\
\hline DMU 20 & 0 & 0 & 0 & 0 & 0 & 0 & 0 & 0.354558865 & 0 & 0 & 0 & 0 & 0 & 0 & 0.323401082 & 0.513790075 \\
\hline DMU 21 & 0 & 0 & 0 & 0 & 0 & 0 & 0 & 0 & 0 & 0 & 0 & 0 & 0 & 0 & 0 & 0 \\
\hline DMU 22 & 0 & 0 & 0 & 0.455021017 & 0.209028333 & 0 & 0 & 0 & 0 & 0.172195816 & 0.807002835 & 0 & 0.572678993 & 0 & 0 & 0 \\
\hline DMU 23 & 0 & 0 & 0 & 0 & 0 & 0 & 0 & 0 & 0 & 0 & 0 & 0 & 0 & 0 & 0 & 0 \\
\hline DMU 24 & 0 & 0 & 0 & 0 & 0 & 0 & 0 & 0 & 0 & 0 & 0 & 0 & 0 & 0 & 0 & 0 \\
\hline DMU 25 & 0 & 0 & 0 & 0 & 0 & 0 & 0 & 0 & 0 & 0 & 0 & 0 & 0 & 0 & 0 & 0 \\
\hline DMU 26 & 0 & 0 & 0 & 0 & 0 & 0 & $0]$ & 0 & 0 & 0 & 0 & 0 & 0 & 0 & 0 & 0 \\
\hline
\end{tabular}

Fig 2. The efficiency reference sets of input-oriented CRS DEA Model for less efficient SUCs

In the CRS DEA model, these ERS weights are generally referred to as Lambda $(\lambda)$ values in the DEA models. These values are used in computing the composite value of less efficient DMUs in order to determine the potential improvement of the identified less efficient DMUs to become efficient.

After solving the ERS, results are used to come up with composite hypothetical values which are then used to make the less efficient DMUs produce more desirable results. These values are obtained by multiplying the ERS of less efficient DMUs to the respective actual values of inputs and outputs of each SUC declared as relatively efficient DMU by CRS model. The composite values are then subtracted to the actual outputs and inputs of the less efficient DMU. The difference of the composite value and the actual value, either negative or positive result, provide the potential improvement for the less efficient DMU to become efficient. Negative result means that the current input or output of the less efficient DMU must be increased to the obtained value to attain efficiency. A positive result, on the other hand, means that the current input or output used by the less efficient DMU must be reduced to the obtained value for the DMU to become efficient. A sample computation is shown in Figures 3 and 4 .

\begin{tabular}{|c|c|c|c|c|c|c|c|c|c|}
\hline & DMU 3 & & & DMU 8 & & & DMU 15 & & COMPOSITE \\
\hline & 25818 & & & 23449 & & & 8521 & & 11894 \\
\hline & 36.8 & & & 32.24 & & & 53.98 & & 25.5592 \\
\hline & 3201 & & & 3524 & & & 1373 & & 1803 \\
\hline \multirow[t]{4}{*}{0.0067} & 1057 & + & 0.4208 & 1250 & + & 0.2176 & 253 & $=$ & 588 \\
\hline & 355943.8 & & & 137282 & & & 89920.8 & & 79719.85514 \\
\hline & 12785.6 & & & 5701.8 & & & 10791.8 & & 4833.27664 \\
\hline & 200 & & & 375 & & & 196.5 & & 201.8984 \\
\hline
\end{tabular}

Fig 3. The calculation of composite in DMU 1 assigned using input-oriented CRS DEA model 


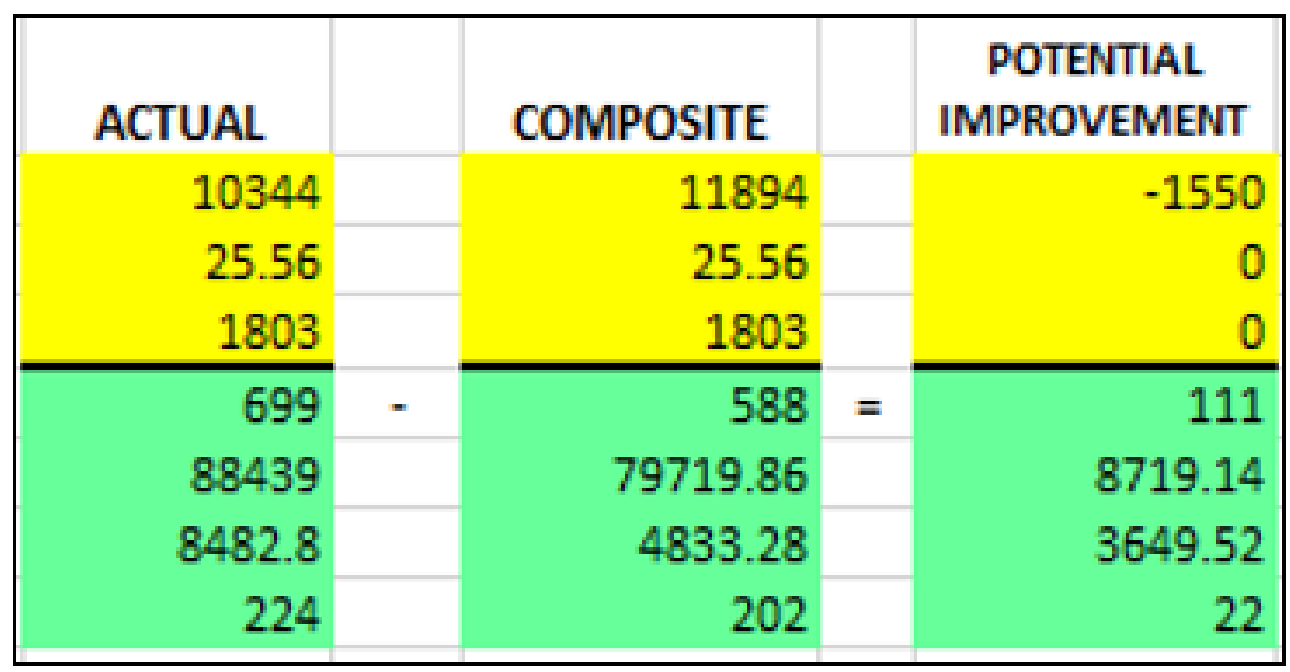

Fig 4. The actual, composite and potential improvement results for DMU 1 calculated using input-oriented CRS DEA model

The values above the lines are the output parameters and below are the input parameters of DMUs. The sum product of the actual inputs and outputs of ERS and the obtained weights by DEA yields the composite schools that will produce as much or more outputs and use lesser inputs which will lead a path to improve the efficiency of the less efficient school.

Figure 3 illustrates that a combination of the parameters used by DMU 3, DMU 8, and DMU 15 would result in a composite theoretical school producing the same or a greater number of outputs as DMU 1. In adopting the combination of the actual parameters utilized by DMU 3, DMU 8 and DMU 15, DMU 1 may reduce its number of faculty by 111, PS+MOOE by P879.14, estimated cost per student by 3649.52 and tuition by P22 in order to become efficient. When this recommendation is followed, this would result to an increase of 1550 in enrolment.

Similarly, potential improvements for DMU 2, DMU 4, DMU 5, DMU 7, DMU 9, DMU 10, DMU 11, DMU 12, DMU 16, DMU 19, DMU 21, DMU 23, DMU 24, DMU 25, and DMU 26 are calculated using input-oriented CRS DEA as shown in Table 5 .

Table 5. Potential improvement results for each DMU calculated using input-oriented CRS DEA

\begin{tabular}{|c|c|c|c|c|c|c|c|}
\hline & ENROLLMENT & $\begin{array}{l}\text { PRC PASSING } \\
\text { RATE }\end{array}$ & GRADUATES & FACULTY & PS+MOOE & $\begin{array}{l}\text { ESTIMATED COST PER } \\
\text { STUDENT }\end{array}$ & TUITION \\
\hline DMU 1 & -1550 & 0 & 0 & 111 & 8719.14 & 3649.52 & 22 \\
\hline DMU 2 & -22 & 0 & 0 & 42 & 82312.95 & 8635.94 & 20.45 \\
\hline DMU 4 & 0 & -7.29 & 0 & 49 & 22493.12 & 5816.36 & 47.6 \\
\hline DMU 5 & 0 & 0 & -139 & 9 & 43429.41 & 5207.53 & 10.95 \\
\hline DMU 7 & 0 & -10.9 & -229 & 22 & 10936.67 & 8557.3 & 27.79 \\
\hline DMU 9 & -206 & 0 & 0 & 2 & 7733.08 & 2938.1 & 4.37 \\
\hline DMU 10 & 0 & 0 & -70 & 112 & 224219.34 & 9489.79 & 152.83 \\
\hline DMU 11 & -1 & 0 & -264 & 89 & 28924.69 & 2830.32 & 164.66 \\
\hline DMU 12 & 0 & 0 & -214 & 5 & 5436.65 & 19487.39 & 162.14 \\
\hline DMU 16 & 0 & 0 & -57 & 66 & 27862.09 & 8455.81 & 155.75 \\
\hline DMU 19 & 0 & 0 & 0 & 51 & 49916.07 & 12212.87 & 145.24 \\
\hline DMU 21 & 0 & -55.37 & 0 & 25 & 176905.41 & 1819.23 & 20.44 \\
\hline DMU 23 & 0 & 0 & -164 & 16 & 24750.8 & 4468.41 & 47.75 \\
\hline DMU 24 & 0 & 0 & -246 & 86 & 39746.72 & 5076.69 & 129.33 \\
\hline DMU 25 & 0 & -16.48 & 0 & 39 & 45198.61 & 1723.22 & 35.32 \\
\hline DMU 26 & 0 & 0 & -244 & 35 & 33603.55 & 1749.25 & 104.22 \\
\hline
\end{tabular}


Figure 5 shows the ERS weights of the efficient DMU against the less efficient DMUs evaluated for the VRS DEA model. These values are used in calculating the composite values of less efficient DMUs in order to determine the potential improvement of the less efficient DMUs that were identified to become efficient.

\begin{tabular}{|c|c|c|c|c|c|c|c|c|c|c|c|c|}
\hline \multicolumn{13}{|c|}{ EFFICIENCY REFERENCE SETS (ERS) } \\
\hline & DMU2 & DMU 4 & DMU5 & DMU7 & DMU9 & DMU 12 & DMU 16 & DMU 19 & DMU 23 & पMU24 & पMU25 & पMU 26 \\
\hline DMU1 & 0 & 0 & 0 & 0 & 0 & 0 & 0 & 0 & 0 & 0 & 0 & 0 \\
\hline DMU2 & 0 & 0 & 0 & 0 & 0 & 0 & 0 & 0 & 0 & 0 & 0 & 0 \\
\hline DMU 3 & 0.25339883 & 0.05505243 & 0 & 0.06313196 & 0 & 0 & 0 & 0 & 0 & 0 & 0 & 0 \\
\hline DMU 4 & 0 & 0 & 0 & 0 & 0 & 0 & 0 & 0 & 0 & 0 & 0 & 0 \\
\hline DMU 5 & 0 & 0 & 0 & 0 & 0 & 0 & 0 & 0 & 0 & 0 & 0 & 0 \\
\hline DMU 6 & 0 & 0 & 0 & 0 & 0.22631298 & 0 & 0.1910851 & 0.0343772 & 0 & 0 & 0.15352657 & 0 \\
\hline DMU 7 & 0.16509819 & 0 & 0 & 0 & 0 & 0 & 0 & 0 & 0 & 0 & 0 & 0 \\
\hline DMU 8 & 0 & 0 & 0 & 0 & 0 & 0 & 0 & 0 & 0 & 0 & 0 & 0 \\
\hline DMU 9 & 0 & 0 & 0 & 0 & 0 & 0 & 0 & 0 & 0 & 0 & 0 & 0 \\
\hline DMU 10 & 0 & 0 & 0 & 0 & 0 & 0 & 0 & 0 & 0 & 0 & 0 & 0 \\
\hline DMU 11 & 0 & 0 & 0 & 0 & 0 & 0 & 0 & 0 & 0 & 0 & 0 & 0 \\
\hline DMU 12 & 0 & 0 & 0 & 0 & 0 & 0 & 0 & 0 & 0 & 0 & 0 & 0 \\
\hline DMU 13 & 0 & 0.22709368 & 0.01494354 & 0 & 0.61223508 & 0.96162403 & 0.73277559 & 0.00619701 & 0.50374806 & 0.20222416 & 0 & 0 \\
\hline DMU 14 & 0 & 0 & 0 & 0 & 0.08706051 & 0.03837597 & 0 & 0.01395399 & 0 & 0 & 0 & 0 \\
\hline DMU 15 & 0.35863654 & 0.34022237 & 0.41108379 & 0 & 0.07439143 & 0 & 0.07613931 & 0.1384708 & 0 & 0.70583743 & 0.08489714 & 0.03370986 \\
\hline DMU 16 & 0 & 0 & 0 & 0 & 0 & 0 & 0 & 0 & 0 & 0 & 0 & 0 \\
\hline DMU 17 & 0 & 0 & 0 & 0 & 0 & 0 & 0 & 0 & 0 & 0 & 0 & 0.06776748 \\
\hline DMU 18 & 0 & 0 & 0.14546987 & 0 & 0 & 0 & 0 & 0 & 0.16437251 & 0 & 0.08089002 & 0.45861692 \\
\hline DMU 19 & 0 & 0 & 0 & 0 & 0 & 0 & 0 & 0 & 0 & 0 & 0 & 0 \\
\hline DMU 20 & 0 & 0 & 0 & 0 & 0 & 0 & 0 & 0 & 0 & 0 & 0 & 0.43990575 \\
\hline DMU 21 & 0 & 0 & 0 & 0 & 0 & 0 & 0 & 0 & 0 & 0 & 0.51760015 & 0 \\
\hline DMU 22 & 0.22286643 & 0.37763152 & 0.4285028 & 0.93686804 & 0 & 0 & 0 & 0.80700101 & 0.33187944 & 0.09193841 & 0.16308612 & 0 \\
\hline DMU 23 & 0 & 0 & 0 & 0 & 0 & 0 & 0 & 0 & 0 & 0 & 0 & 0 \\
\hline DMU 24 & 0 & 0 & 0 & 0 & 0 & 0 & 0 & 0 & 0 & 0 & 0 & 0 \\
\hline $\mathrm{DMU} 25$ & 0 & 0 & 0 & 0 & 0 & 0 & 0 & 0 & 0 & 0 & 0 & 0 \\
\hline DMU 26 & 0 & 0 & 0 & 0 & 0 & 0 & 0 & 0 & 0 & 0 & 0 & 0 \\
\hline
\end{tabular}

Fig 5. The efficiency reference sets of input-oriented VRS DEA Model for less efficient SUCs

Figures 6 and 7 illustrate that a combination of the parameters used by DMU 3, DMU 6, DMU 15 and DMU 22 would result in a composite theoretical school producing the same or a greater number of outputs as DMU 2. Thus, in adopting the combination of the actual parameters by DMU 3, DMU 6, DMU 15 and DMU 22, DMU 2 may reduce its number of faculty by 31, PS+MOOE by Php76015.33, estimated cost per student by Php6449.75 and tuition fee by Php15.27 Thus, an increase of 556 in its enrolment can be obtained as shown in Figure 7.

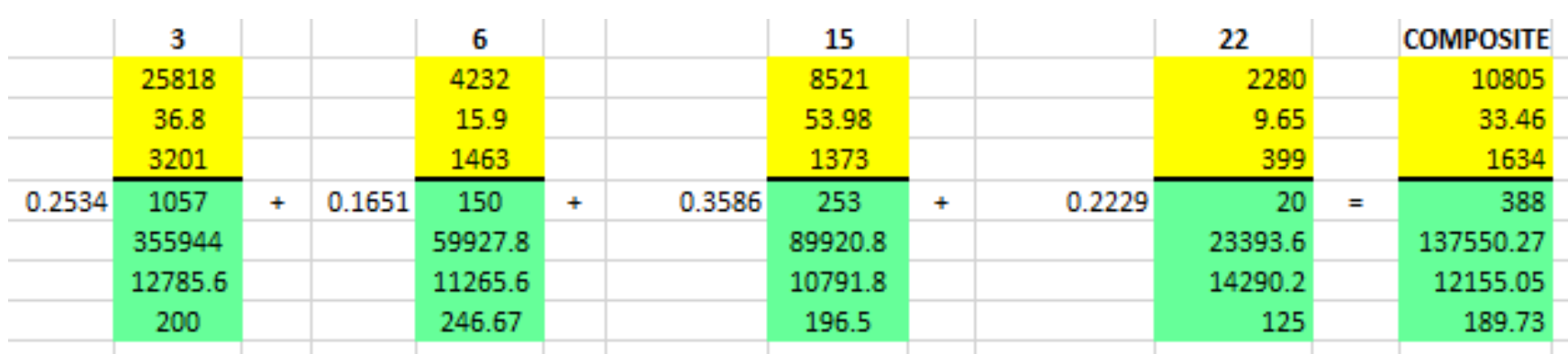

Fig 6. The calculation of composite in DMU 2 assigned using input-oriented VRS DEA model

In computing the other less efficient schools, similar calculation is done. Hence, we obtain potential improvements for DMU 2, DMU 4, DMU 5, DMU 7, DMU 9, DMU 12, DMU 16, DMU 19, DMU 23, DMU 24, DMU 25, and DMU 26 are calculated using input-oriented VRS DEA, as shown in Table 6. 
Table 6. Potential improvement results for each DMU calculated using input-oriented VRS

\begin{tabular}{llllllll}
\hline & ENROLLMENT & $\begin{array}{l}\text { PRC PASSING } \\
\text { RATE }\end{array}$ & GRADUATES & FACULTY & PS+MOOE & \multicolumn{2}{l}{$\begin{array}{l}\text { ESTIMATED COST } \\
\text { PER STUDENT }\end{array}$} \\
\hline DMU 2 & -556 & 0 & & & & TUITION \\
DMU 4 & -19 & -14.95 & 0 & 31 & 76015.33 & 6449.75 & 15.27 \\
DMU 5 & 0 & 0 & -136 & 9 & 22622.89 & 2550.41 & 32.54 \\
DMU 7 & 0 & -6.68 & -227 & 25 & 43108.65 & 5263.38 & 10.78 \\
DMU 9 & -86 & 0 & 0 & 2 & 5744.28 & 2955.74 & 7.77 \\
DMU 12 & -1044 & 0 & -188 & 4 & 22574.91 & 28734.53 & 3.59 \\
DMU 16 & 0 & -7.68 & -216 & 53 & 24637.6 & 6776 & 179.77 \\
DMU 19 & 0 & 0 & 0 & 50 & 49375.09 & 12072.2 & 11.31 \\
DMU 23 & 0 & 0 & -142 & 14 & 22531.46 & 5603.19 & 145.77 \\
DMU 24 & 0 & -4.57 & -272 & 82 & 42057.63 & 4813.71 & 51.72 \\
DMU 25 & 0 & 0 & 0 & 30 & 13792.11 & 2206.51 & 126.16 \\
DMU 26 & 0 & 0 & -225 & 34 & 25604.96 & 1695.02 & 31.55 \\
\hline
\end{tabular}

\begin{tabular}{|c|c|c|c|c|}
\hline ACTUAL & & COMPOSITE & & $\begin{array}{c}\text { POTENTIAL } \\
\text { IMPROVEMENT }\end{array}$ \\
\hline 10249 & & 10805 & & -556 \\
\hline 33.46 & & 33.46 & & 0 \\
\hline 1634 & & 1634 & & 0 \\
\hline 419 & - & 388 & $=$ & 31 \\
\hline 213565.6 & & 137550.27 & & 76015.33 \\
\hline 18604.8 & & 12155.05 & & 6449.75 \\
\hline 205 & & 189.73 & & 15.27 \\
\hline
\end{tabular}

Fig 7. The actual, composite and potential improvement results for DMU 2 calculated using input-oriented VRS DEA model

In cases when improvements suggested by this study involve reduction of resources, such can also be viewed as a hint for the SUC to increase the other input parameters in order to increase efficiency of the entire DMU. For example, when it is found that there is an excess in the number faculty members, it may be viewed as a hint for the SUC to improve its enrolment, performance in the board exams and number of graduates in order to increase its efficiency. It does not necessarily mean literally reducing the current number of teachers.

\section{Conclusions}

In this study, the input minimizing DEA approach utilizing the structure of return to scale of DEA model which are the inputoriented CRS model and VRS model is used to measure the relative efficiency of SUCs in Southern Philippines. The two scale models are used in this study because it is uncertain that SUCs operate at optimal scale. The DMUs of this study are select SUCs in Southern Philippines covering the period 2012-2016 using four input and three output parameters.

Results of the study showed that among the 26 SUCs considered in this study, only ten (10) SUCs are found to be efficient while the sixteen (16) SUCs are less efficient under the input-oriented CRS model. On the other hand, in the input-oriented VRS model, thirteen (13) SUCs are identified efficient and the remaining thirteen (13) are less efficient. The distinction of results obtained from the two scale models are due to the fact that CRS tends to lower the efficiency score while the VRS tends to raise the efficiency score. Potential improvements are needed for less efficient SUCs to adopt the Efficiency Reference Set (ERS) weights of the identified efficient SUCs against the less efficient SUCs in order to improve efficiency.

It may be interesting to consider other parameters to better assess the efficiency of the SUCs. Unfortunately, this poses a challenge in the procurement of data. Moreover, just recently, the Philippines implemented RA 10931 (Free Higher Education 
for Filipinos), which gives free education to students enrolling in SUCs around the country. Evaluating the effect of RA 10931 is hereby mentioned as a possible future work for this paper. This is due to the fact that for DEA to give better results, there is a need to work with a data set obtained for at least 5 years in the implementation of this act.

\section{References}

1) Cuenca JS. Efficiency of State Universities and Colleges in the Philippines: a Data Envelopment Analysis. Discussion Papers DP 2011-14, Philippine Institute for Development Studies. 2011. Available from: https://ideas.repec.org/p/phd/dpaper/dp_2011-14.html.

2) Stupnytskyy O, Center for Economic Research and Graduate Education and the Economics Institute. Secondary Schools Efficiency in the Czech Republic. Prague. 2004. Available from: https://www.eldis.org/document/A15984.

3) Maragos E, Despotis D. Evaluation of High Schools performance: A data envelopment analysis approach. In: Proceedings of the APORS2003 International Conference;vol. 2. 2003;p. 435-442. Available from: http://citeseerx.ist.psu.edu/viewdoc/download?doi=10.1.1.650.3298\&rep=rep1\&type=pdf.

4) Namoco RA, Pailagao RO, and. Examining the efficiency of selected private hospitals in Southern Philippines using data envelopment analysis. Indian Journal of Science and Technology. 2017;10(43):1-7. Available from: https://dx.doi.org/10.17485/ijst/2017/v10i43/118233.

5) Charles A, Copper W, Lewin A, Seiford L. Data Envelopment Analysis: Theory, Methodology, and Application. and others, editor;Kluwer Academic Publisher. 1994. Available from: https://www.springer.com/gp/book/9780792394792.

6) Saati S, Marbini AH, Tavana M. Data envelopment analysis: an efficient duo linear programming approach. International Journal of Productivity and Quality Management. 2011;7(1):90-103. Available from: https://dx.doi.org/10.1504/ijpqm.2011.037733.

7) Guzman MCGND, Cabanda E. Selected private higher educational institutions in Metro Manila: A DEA efficiency measurement. American Journal of Business Education (AJBE). 2009;2(6):97-108. Available from: https://dx.doi.org/10.19030/ajbe.v2i6.4092.

8) Bifulco R, Duncombe W. Evaluating School Performance: Are We Ready for Prime Time. In: Fowler WJ, et al., editors. Developments in School Finance 1999-2000. 2002;p. 11-28. Available from: http://citeseerx.ist.psu.edu/viewdoc/download?doi=10.1.1.219.7558\&rep=rep1\&type=pdf.

9) Castano M, Caroline N, Cabanda, Emilyn C. Sources of efficiency and productivity growth in the Philippine State Universities and Colleges: A nonparametric approach. International Business and Economics Research Journal. 2007;6(6):79-90. Available from: https://doi.org/10.19030/iber.v6i6.3379. 